\title{
Iron-Catalyzed Alkylations of Aromatic Grignard Reagents
}

Synthesis

\section{Key words}

iron

alkylation

Grignard reagents

cross-coupling

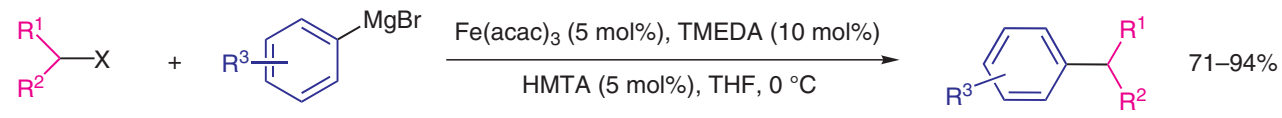

(1.3 equiv) $\quad \mathrm{R}^{1}=\mathrm{Alk} ; \mathrm{R}^{2}=\mathrm{H}, \mathrm{Alk} ; \mathrm{R}^{3}=\mathrm{H}, \mathrm{MeO}, \mathrm{Me}_{2} \mathrm{~N} ; \mathrm{X}=\mathrm{Br}, \mathrm{I}$
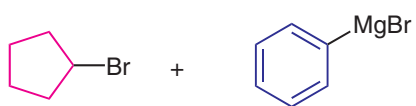

$\mathrm{Fe}(\mathrm{acac})_{3}(5 \mathrm{~mol} \%)$, TMEDA (10 mol\%) HMTA (5 mol\%), THF, $0{ }^{\circ} \mathrm{C}, 45 \mathrm{~min}$

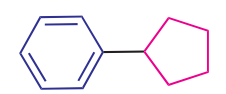<smiles>CCCC(Br)CC</smiles><smiles></smiles><smiles>CCCC(CC)c1ccc(N(C)C)cc1</smiles>
$85 \%$

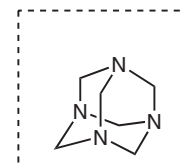

HMTA<smiles>CCCBr</smiles><smiles>COc1ccc(N(Br)Br)cc1</smiles>

same conditions

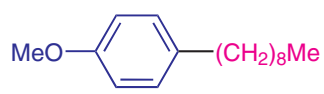

$72 \%$

$78 \%$

Significance: The development of iron-catalyzed cross-coupling reactions is an extremely promising field of research, taken into account the importance of this method for current organic synthesis and the multiple problems connected with commonly used $\mathrm{Pd}$ - and $\mathrm{Ni}$-catalyzed processes. The group of Cahiez reported the first iron-catalyzed alkyl-aryl cross-coupling reaction, suitable for industrial large-scale applications. It uses only a small amount of cheap ligands TMEDA and HMTA and THF as the solvent and does not require cryogenic conditions.
Comment: This is an interesting example of the application of hexamethylenetetramine (HMTA) as ligand in transition-metal catalysis. The problem to find suitable ligands for iron-catalyzed cross-coupling attracts currently significant attention, however, until now the results are far from the progress achieved in Pd catalysis. The exact oxidative state of iron in this catalytic cycle has not yet been determined, and catalytic cycles between $\mathrm{Fe}^{\mathrm{l}} / \mathrm{Fe}^{\mathrm{III}}$ and $\mathrm{Fe}^{-11} / \mathrm{Fe}^{0}$ are discussed. Primary and secondary alkyl bromides react equally well in this process. 